\title{
Establishment and characterization of a chimeric infectious cDNA clone of classical swine fever virus
}

\author{
T. S. ZHAO시 Y. H. XIA² \\ ${ }^{1}$ School of Pharmacy, Nanchang University, Nanchang 330006, Jiangxi, P. R. China; ${ }^{2}$ Department of Medical Microbiology, School \\ of Medicine, Nanchang University, Nanchang 330006, Jiangxi, P. R. China
}

Received August 3, 2015; revised September 29, 2015; accepted April 21, 2016

\begin{abstract}
Summary. - Classical swine fever virus (CSFV) causes a highly contagious disease among swine that has an important economic impact worldwide. There are two important CSFV strains in China, Shimen and hog cholera lapinized virus (HCLV). Shimen strain is highly virulent while HCLV, also referred to as C-strain, is a live attenuated vaccine strain considered to be one of the most effective and safest live vaccines. In this study, a chimeric infectious cDNA clone of CSFV named pT7SM-c was engineered by replacing the $\mathrm{E}^{\text {rns }}$ genomic region of an infectious clone of CSFV Shimen strain, pT7SM, with the same region obtained from HCLV. RNA transcripts of pT7SM-c containing an engineered EcoRI site that served as a genetic marker were directly infectious in PK15 cells. The rescued virus vT7SM-c showed similar growth kinetics and cytopathic effect with the parental virus vT7SM in the cells. The chimeric infectious cDNA clone can be used as a practical tool for further studying of the virulence, protein function and pathogenesis of CSFV through genetic manipulation.
\end{abstract}

Keywords: classical swine fever virus; chimeric infectious cDNA clone; $\mathrm{E}^{\mathrm{rns}}$

\section{Introduction}

Classical swine fever virus (CSFV) is the etiological agent of classical swine fever (CSF), also known as hog cholera, a devastating disease of swine and wild boar, which causes significant economic losses in the pig industry worldwide. CSFV, together with bovine viral diarrhea virus (BVDV) and border disease virus (BDV) constitutes the genus Pestiviruses within the family Flaviviridae (Thiel et al., 1991; Becher and Thiel, 2002). Like other members of the genus Pestiviruses, CSFV is a small enveloped virus with a positive-sense singlestranded RNA genome of about $12.3 \mathrm{~kb}$ in length, which contains 5 'untranslated region (UTR), 3'UTR and one open reading frame (ORF) coding for a polyprotein of about 3898 amino acids. The viral polyprotein is co- and post-transla-

*Corresponding author. E-mail: xyh36@163.com; phone: +86791-83827093.

Abbreviations: CSFV $=$ classical swine fever virus; $\mathrm{HCLV}=$ hog cholera lapinized virus; PK15 = porcine kidney 15 cells tionally processed by both viral and host proteases into 12 mature proteins including $\mathrm{N}^{\text {pro }}, \mathrm{C}, \mathrm{E}^{\mathrm{rns}}, \mathrm{E} 1, \mathrm{E} 2, \mathrm{p} 7, \mathrm{NS} 2, \mathrm{NS} 3$, NS4A, NS4B, NS5A and NS5B (Rumenapf et al., 1993).

The effective prevention and control of CSF usually depends on HCLV vaccine in China and many other countries of the world. The HCLV strain is a live attenuated vaccine strain that was obtained from the highly virulent strain of CSFV by 480 passages in rabbits in China during the 1950s. However, the mechanism of attenuation of this successful vaccine strain is still unknown. Recently, studies of determinants of virulence and attenuation mechanism of CSFV progress rapidly, which is attributed to the successful construction of infectious cDNA clones of CSFV (Meyers et al., 1996; Ruggli et al., 1996; de Smit et al., 2000; Wu et al., 2003; Park et al., 2012). As reported, the deletion of the viral gene $\mathrm{N}^{\text {pro }}$ would lead to CSFV attenuation (Mayer et al., 2004), E2 glycoprotein of CSFV was a virulence determinant, while E1 glycoprotein of CSFV would affect viral virulence in swine (Risatti et al., 2005a,b), and the introduction of a continuous 12-nt (CUUUUUUCUUUU) insertion in viral 3' UTR might be a novel attenuation mechanism of CSFV (Wang et al., 2008). 
$\mathrm{E}^{\mathrm{rns}}$, a structural protein of CSFV with RNase activity (Hulst et al., 1998), was found to induce apoptosis in lymphocytes of several species (Bruschke et al., 1997). Since pestivirus infection is characterized by leukocyte reduction and immunosuppression, $\mathrm{E}^{\mathrm{rns}}$ is considered to be associated with the pathogenesis of CSFV. Further studies indicated that inactivation of the RNase activity of CSFV $E^{\text {rns }}$ resulted in cytopathic effect and virus attenuation in swine (Hulst et al., 1998; Meyers et al., 1999). However, $E^{\text {rns }}$ shows RNase activity in both virulent and avirulent CSFV strains. Obviously, RNase activity of $\mathrm{E}^{\mathrm{rns}}$ is not a good explanation to $\mathrm{HCLV}$ attenuation. In order to investigate the role of $\mathrm{E}^{\mathrm{rns}}$ in CSFV attenuation, a chimeric infectious cDNA clone was constructed that contains all genetic regions of Shimen strain except that of $\mathrm{E}^{\mathrm{rns}}$ from HCLV strain. This chimeric infectious cDNA clone can be used as a practical tool for further studying the virulence, protein function and pathogenesis of CSFV.

\section{Materials and Methods}

Viruses and cells. The porcine kidney 15 (PK15) cell line was obtained from China Center for Type Culture Collection. PK15 cells were cultured in Dulbecco's Modified Eagle Medium (DMEM) with $10 \%$ fetal calf serum, penicillin $(100 \mathrm{U} / \mathrm{ml})$ and streptomycin $(100 \mu \mathrm{g} / \mathrm{ml})$. Cells were maintained at $37^{\circ} \mathrm{C}$ in a humidified atmosphere containing $5 \%$ of $\mathrm{CO}_{2}$. The CSFV highly virulent strain Shimen and vaccine strain HCLV were provided by China Institute of Veterinary Drug Control.

Construction of chimeric cDNA clone. An infectious cDNA clone of CSFV strain Shimen named pT7SM was constructed previously (Wu et al., 2003). Seven cDNAs amplified by reverse-transcriptase PCR (RT-PCR) were cloned into the low-copy-number plasmid pBR322 to obtain pT7SM. Gene $E^{\text {rns }}$ is located in cDNA2.
Utilizing the swinging of the third base in a code, the $\mathrm{T}$ at site 1219 was replaced with A to create a unique EcoRI restriction site (GGAATTCAG) in $\mathrm{E}^{\text {rns }}$ genetic region of $\mathrm{cDNA} 2$ with the primer pairs of 5'-CCACATGATAGGGGGAGAGG-3' and 5'-CGTTAC CTTAAGTCGTACGAT-3'; 5'-CGGAATTCAGCATGCTATG TACC-3' and 5'-GGGGCACCAAACCAGGTTTTGCTT-3'. Gene $\mathrm{E}^{\text {rns }}$ from the HCLV strain of CSFV was amplified using RT-PCR with a primer pair of 5'-CGGAATTCAGCATGCTATGTACC-3' and 5'- GGGGCACCAAACCAGGTTTTGCTT-3'. The genomic region of $E^{\text {rns }}$ of plasmid pT7SM was replaced with the amplified $\mathrm{E}^{\mathrm{rns}}$ from HCLV strain to generate a chimeric clone pT7SM-c by using restriction enzymes EcoRI and BshN1 (NEB, USA) (Fig. 1a).

Rescue of viruses. Full-length genomic clone pT7SM and pT7SM-c were linearized with SacII and the 3' UTR end of SacII site was blunted by T4 DNA polymerase (NEB, USA). Then the linearized clones were in vitro transcribed by the T7 RNA polymerase (Promega, USA). After removing the DNA template by DNase I (RNase free) (Promega, USA), the RNA transcripts were mixed with $10 \mu$ l Lipofectin2000 (Invitrogen) for transfection on PK15 monolayer in 6-well cell plate for $6 \mathrm{hr}$. Then the cells were maintained in Dulbecco's Modified Eagle Medium (4\% fetal calf serum) for $48 \mathrm{hr}$. The viruses recovered from full-length clones were named vT7SM and vT7SM-c, respectively.

The transfected cell cultures were frozen and thawed for three times for re-infection on PK15 cells to check the infectivity of clones. After five passages, the infection in cell culture was detected by RT-PCR. Furthermore, indirect immunofluorescence assay was performed to make sure that vT7SM and vT7SM-c were rescued in the cells by using the CSFV-specific rabbit anti- $\mathrm{E}^{\text {rns }}$ serum (Chen $e t$ al., 2007) as primary antibody and mouse anti-Rabbit Rhodamineconjugated IgG as secondary antibody (Beijing Zsbio).

Growth curves of Shimen, vT7SM and vT7SM-c on PK15 cells. Growth kinetics of the chimeric virus and parental strains was characterized by infection of PK15 cells seeded in a 6 well plate $(\mathrm{MOI}=0.1)$. Culture supernatant was collected at $12,24,36,48$, (a)

\begin{tabular}{|c|c|c|c|c|c|c|c|c|c|c|c|}
\hline pT7SM & 5'UTR & $\mathbf{N}^{\text {pro }}$ & $\mathbf{C}$ & $\mathbf{E}^{\text {ms }}$ & E1 & E2 & p7 & NS2-3 & NS4AB & NS5AB & 3'UTR \\
\hline \multicolumn{12}{|c|}{ EcoR1 } \\
\hline pT7SM-c & 5'UTR & Npro & $\mathbf{C}$ & $\mathbf{E}^{\mathrm{ms}}$ & E1 & E2 & p7 & NS2-3 & NS4AB & NS5AB & 3'UTR \\
\hline
\end{tabular}

HCLV

\begin{tabular}{|l|l|l|l|l|l|l|l|l|l|l|}
\hline 5'UTR & Nmw & C & E'ms & E1 & E2 & p7 & NS2-3 & NS4AB & NS5AB & 3'UTR \\
\hline
\end{tabular}

(b) XDNA/

HindIII BamH I Kpn I EcoR I HindIII

Fig. 1

Construction and identification of chimeric full-length cDNA clone pT7SM-c

(a) A schematic genome figure of chimeric and parental strains and construction of chimeric cDNA clone. The genomic regions of parental viruses, pT7SM (blank) and HCLV (gray), and the locations of the restriction enzyme sites used for genetic manipulation are indicated. (b) Identification of pT7SM-c by enzyme digestion. 
Table 1. Distribution of enzyme restriction sites in pT7SM-c

\begin{tabular}{ccc}
\hline Restriction enzyme & Restriction site (nt) & Band size after digestion (bp) \\
\hline BamHI & 6436 & $7074+8964$ \\
KpnI & 4448,11522 & $6591+4956+4345+237$ (not seen) \\
EcoRI & $1217^{*}, 5562,5799,1299$ & $6017+5062+4456+503$ (not seen) \\
HindIII & $752,1255,5711,11728$ & \\
\hline
\end{tabular}

EcoRI restriction site at $1217^{*}$ was introduced into $\mathrm{E}^{\text {rns }}$ to facilitate the genetic segment exchange.

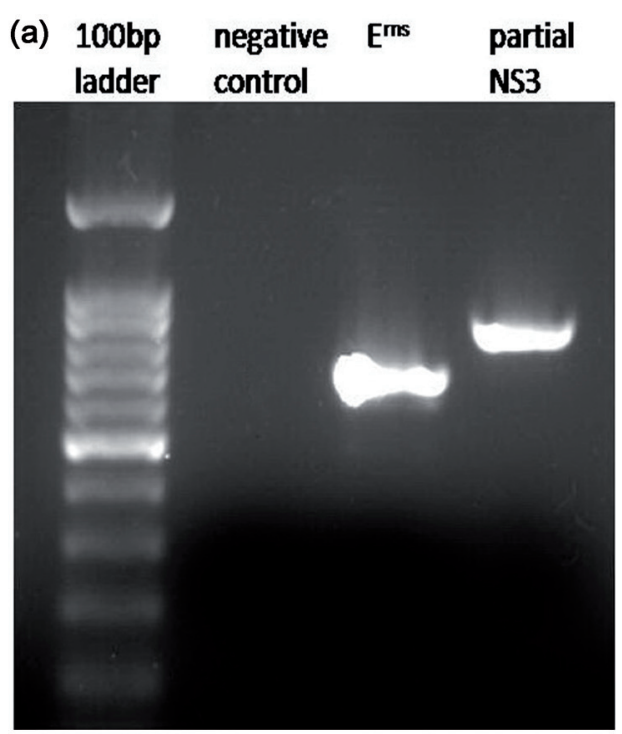

Identification of chimeric virus vT7SM-c

(a) RT-PCR detecting vT7SM-c in infected cells. (b) Indirect immunofluorescence analysis of vT7SM-c-infected cells using CSFV-specific antibody. (b)

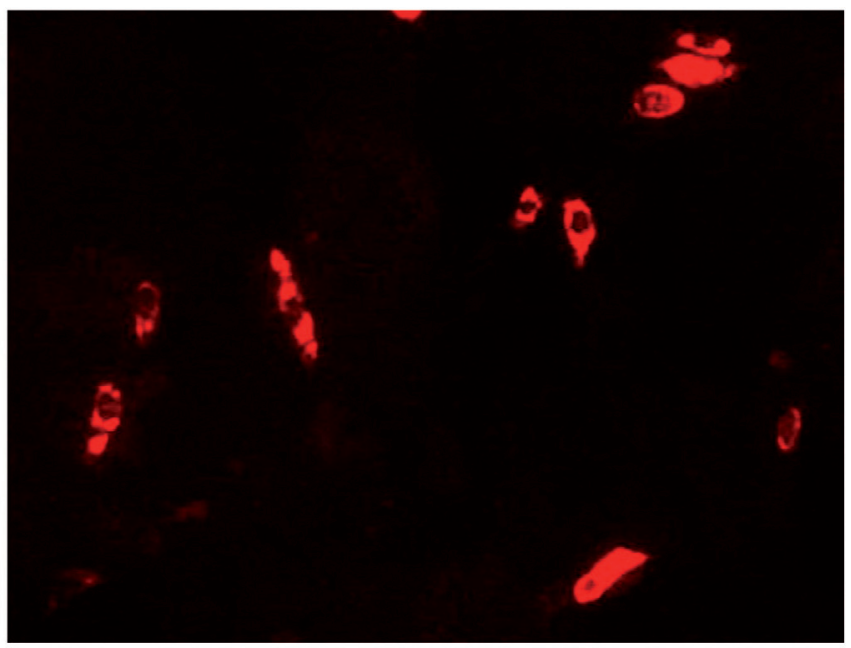

Fig. 2
60 , and $72 \mathrm{hr}$ post-infection, and viral titers in the supernatant were determined and expressed as PFU/ml in PK15 cells.

\section{Results}

Construction of chimeric full-length cDNA clone

The chimeric full-length cDNA clone pT7SM-c was constructed from pT7SM as described in Materials and methods (Fig. 1a) and identified by enzyme digestion (Fig. 1b). The distribution of enzyme restriction sites in PT7SM-c is shown in Table. 1.

\section{Rescue of chimeric virus}

RNA transcripts obtained from clone pT7SM and pT7SM-c were used to transfect PK15 cells and the rescued viruses were named vT7SM and vT7SM-c, respectively. The

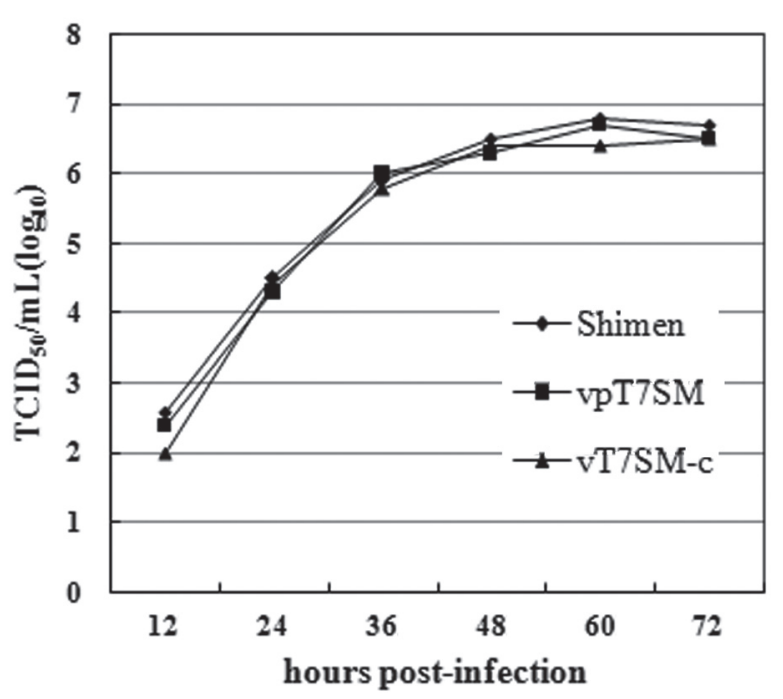

Fig. 3

Growth kinetics of chimeric and parental strains on PK15 cells 
cell culture infected by vT7SM and vT7SM-c did not show any cytopathic effect (CPE), which was similar to the infection with Shimen strain (data not shown). After five passages, viral genetic fragments of $\mathrm{E}^{\mathrm{rns}}$ and partial non-structural NS3 were detected by RT-PCR (Fig. 2a) and virus-specific antigen of $\mathrm{E}^{\text {rns }}$ was detected by indirect immunofluorescence assay (Fig. 2b), demonstrating the infectivity and stability of vT7SM-c.

\section{Growth kinetics of chimeric virus on PK15 cells}

One-step growth curve was drawn to compare the growth kinetics of chimeric virus vT7SM-c with that of its parental virus vT7SM and Shimen. As shown in Fig. 3, the growth characteristics of Shimen, vT7SM and vT7SM-c were almost undistinguished.

\section{Discussion}

Here, we described the construction of a chimeric infectious cDNA clone of CSFV. Its biological characteristics were evaluated based on in vitro growth properties and CPE on PK15 cells.

A full-length cDNA clone that rescues infectious viral progeny would be an excellent tool for the functional characterization of viral gene products, analysis of virus and RNA replication, determination of virulence factors, and elucidation of mechanisms involved in viral pathogenesis. Recently, investigation of the genetic basis and the molecular mechanism of virulence and viral attenuation based on full-length cDNA clones becomes a fascinating focus in CSFV research. Previously, researches have proposed various mechanisms for different virulence determinants of CSFV (La Rocca et al., 2005; Risatti et al., 2005a,b; Hilton et al., 2006; Risatti et al., 2007; Wang et al., 2008).

As reported, abrogating of $\mathrm{E}^{\mathrm{rns}} \mathrm{RNase}$ activity led to CSFV attenuation (Meyers et al., 1999). However, $\mathrm{E}^{\mathrm{rns}}$ shows RNase activity in both virulent and avirulent CSFV strains, which has not yet demonstrated whether the genetic region of $\mathrm{E}^{\mathrm{rns}}$ was involved in affecting viral virulence. Sequence alignment analysis reveals that sequence difference exists in Shimen $\mathrm{E}^{\mathrm{rns}}$ and HCLV $\mathrm{E}^{\mathrm{rns}}$ (data not shown), so we wonder whether the attenuation of HCLV is a result of $E^{\text {rns }}$ mutation. In this study, we constructed a chimeric infectious cDNA full-length clone of CSFV named pT7SM-c by replacing the $\mathrm{E}^{\text {rns }}$ genomic region of an infectious clone of CSFV Shimen strain, pT7SM, with the same region obtained from HCLV.

We observed that the rescued chimeric virus vT7SM-c showed no CPE on PK15 cells and had similar growth characteristic as its parental virus. Recent studies have revealed several potential pathogenic mechanisms of viruses, including factors that increase viral replication capacity and suppress host innate immunity, for example, polymerase polymorphisms of influenza virus increased viral polymerase activity and virulence (Gabriel et al., 2014; RodriguezFrandsen et al., 2015; Shao et al., 2015). As we know, the vaccine strain HCLV replicates in an almost imperceptible level compared with other virulent strains, such as Shimen. Hence, the down-regulated replication capacity might be an important factor associated with virus virulence. However, no change was observed in replication capacity of vT7SM-c, which means gene mutation found in $\mathrm{E}^{\text {rns }}$ might not be a necessary determinant to CSFV virulence.

In conclusion, we created vT7SM-c from a chimeric infectious cDNA clone of CSFV and compared its growth properties with that of the parental strain. This clone will provide an opportunity for genetic manipulation of CSFV and studying of the virulence, protein function and pathogenesis of CSFV.

Acknowledgements. This work was supported by Natural Science Foundation of Jiangxi Province in China (20142BAB205070).

\section{References}

Becher P, Thiel HJ (2002): Genus Pestivirus (Flaviviridae). In Tidona CA, Darai G (Eds): The Springer Index of Viruses. Springer, Heidelberg, pp. 327-331. http://dx.doi. org/10.1007/3-540-31042-8 53

Bruschke CJ, Hulst MM, Moormann RJ, van Rijn PA, van Oirschot JT (1997): Glycoprotein Erns of pestiviruses induces apoptosis in lymphocytes of several species. J. Virol. 71, 6692-6696.

Chen L, Xia YH, Pan ZS, Zhang CY (2007): Expression and functional characterization of classical swine fever virus Erns protein. Protein. Expr. Purif. 55, 379-387. http://dx.doi. org/10.1016/j.pep.2007.05.003

de Smit AJ, van Gennip HG, Miedema GK, van Rijn PA, Terpstra C, Moormann RJ (2000): Recombinant classical swine fever (CSF) viruses derived from the Chinese vaccine strain (C-strain) of CSF virus retain their avirulent and immunogenic characteristics. Vaccine 18, 2351-2358. http://dx.doi.org/10.1016/S0264-410X(00)00027-X

Gabriel G, Fodor E (2014): Molecular determinants of pathogenicity in the polymerase complex. Curr. Top. Microbiol. Immunol. 385, 35-60. http://dx.doi.org/10.1007/82_2014_386

Hilton L, Moganeradj K, Zhang G, Chen YH, Randall RE, McCauley JW, Goodbourn S (2006): The NPro product of bovine viral diarrhea virus inhibits DNA binding by interferon regulatory factor 3 and targets it for proteasomal degradation. J. Virol. 80, 11723-11732. http://dx.doi.org/10.1128/JVI.01145-06

Hulst MM, Panoto FE, Hoekman A, van Gennip HG, Moormann RJ (1998): Inactivation of the RNase activity of glycoprotein $\mathrm{E}(\mathrm{rns})$ of classical swine fever virus results in a cytopathogenic virus. J. Virol. 72, 151-157.

La Rocca SA, Herbert RJ, Crooke H, Drew TW, Wileman TE, Powell PP (2005): Loss of interferon regulatory factor 3 in cells 
infected with classical swine fever virus involves the Nterminal protease, Npro. J. Virol. 79, 7239-7247. http:// dx.doi.org/10.1128/JVI.79.11.7239-7247.2005

Mayer D, Hofmann MA, Tratschin JD (2004): Attenuation of classical swine fever virus by deletion of the viral $\mathrm{N}$ (pro) gene. Vaccine 22, 317-328. http://dx.doi.org/10.1016/j. vaccine.2003.08.006

Meyers G, Saalmüller A, Büttner M (1999): Mutations abrogating the RNase activity in glycoprotein $\mathrm{E}$ (rns) of the pestivirus classical swine fever virus lead to virus attenuation. J. Virol. 73, 10224-10235.

Meyers G, Thiel HJ, Rümenapf T (1996): Classical swine fever virus: recovery of infectious viruses from cDNA constructs and generation of recombinant cytopathogenic defective interfering particles. J. Virol. 70, 1588-1595.

Park GS, Lim SI, Hong SH, Song JY (2012): Establishment and characterization of an infectious cDNA clone of a classical swine fever virus LOM strain. J. Vet. Sci. 13, 81-91. http://dx.doi.org/10.4142/jvs.2012.13.1.81

Risatti GR, Borca MV, Kutish GF, Lu Z, Holinka LG, French RA, Tulman ER, Rock DL (2005a): The E2 glycoprotein of classical swine fever virus is a virulence determinant in swine. J. Virol. 79, 3787-3796. http://dx.doi.org/10.1128/ IVI.79.6.3787-3796.2005

Risatti GR, Holinka LG, Lu Z, Kutish GF, Tulman ER, French RA, Sur JH, Rock DL, Borca MV (2005b): Mutation of E1 glycoprotein of classical swine fever virus affects viral virulence in swine. Virology 343, 116-127. http://dx.doi. org/10.1016/j.virol.2005.08.015

Risatti GR, Holinka LG, Fernandez Sainz I, Carrillo C, Lu Z, Borca MV (2007): N-Linked glycosylation status of classical swine fever virus strain Brescia E2 glycoprotein influences virulence in swine. J. Virol. 81, 924-933. http://dx.doi. org/10.1128/JVI.01824-06

Rodriguez-Frandsen A, Alfonso R, Nieto A (2015): Influenza virus polymerase: Functions on host range, inhibition of cellular response to infection and pathogenicity. Virus Res. 209, 23-38. http://dx.doi.org/10.1016/j.virusres.2015.03.017

Rümenapf T, Unger G, Strauss JH, Thiel HJ (1993): Processing of the envelope glycoproteins of pestiviruses. J. Virol. 67, 3288-3294.

Ruggli N, Tratschin JD, Mittelholzer C, Hofmann MA (1996): Nucleotide sequence of classical swine fever virus strain Alfort/187 and transcription of infectious RNA from stably cloned full-length cDNA. J. Virol. 70, 3478-3487.

Shao J, Liang Y, Ly H (2015): Human hemorrhagic Fever causing arenaviruses: molecular mechanisms contributing to virus virulence and disease pathogenesis. Pathogens 4 , 283-306. http://dx.doi.org/10.3390/pathogens4020283

Thiel HJ, Stark R, Weiland E, Rümenapf T, Meyers G (1991): Hog cholera virus: molecular composition of virions from a pestivirus. J. Virol. 65, 4705-4712.

Wang Y, Wang Q, Lu XL, Zhang CY, Fan XZ, Pan ZS, Xu L, Wen GY, Ning YB, Tang FQ, Xia YH (2008): 12-nt insertion in 3 ' untranslated region leads to attenuation of classic swine fever virus and protects host against lethal challenge. Virology 374, 390-398. http://dx.doi.org/10.1016/j. virol.2008.01.008

Wu HX, Zhang CY, Zheng CY, Wang JF, Pan ZS, Li L, Cao S, Yi GH (2003): Construction of cytopathic PK15 cell model of classical swine fever virus. Chin. Sci. Bull. 48, 887-891. http://dx.doi.org/10.1360/02wc0437 